Article

\title{
Improvement in the Sediment Management of a Lagoon Harbor: The Case of Marano Lagunare, Italy
}

\author{
Silvia Bosa *D, Marco Petti and Sara Pascolo \\ Dipartimento Politecnico di Ingegneria e Architettura, University of Udine, 33100 Udine, Italy; \\ marco.petti@uniud.it (M.P.); sara.pascolo@uniud.it (S.P.) \\ * Correspondence: silvia.bosa@uniud.it; Tel.: +39-0432-558715
}

check for updates

Citation: Bosa, S.; Petti, M.; Pascolo, S. Improvement in the Sediment Management of a Lagoon Harbor: The Case of Marano Lagunare, Italy. Water 2021, 13, 3074. https:// doi.org/10.3390/w13213074

Academic Editors: Sylvain Ouillon, Xavier Bertin and Romaric Verney

Received: 17 September 2021

Accepted: 26 October 2021

Published: 2 November 2021

Publisher's Note: MDPI stays neutral with regard to jurisdictional claims in published maps and institutional affiliations.

Copyright: (c) 2021 by the authors. Licensee MDPI, Basel, Switzerland. This article is an open access article distributed under the terms and conditions of the Creative Commons Attribution (CC BY) license (https:// creativecommons.org/licenses/by/ $4.0 /)$.

\begin{abstract}
Port silting is a common and natural process which often causes serious inconveniences for safe navigation and requires expensive dredging operations to keep the port operative. Sediment deposition is closely related to the exchange water between the basin and the surrounding environment; one way to limit deposits is by reducing the flow entering the port. However, this may be in contrast with the need for adequate sediment quality, which in turn is closely related to an appropriate water current. This seems to be particularly important in lagoon environments, where sediments are often polluted, making its disposal more complicated and costly. The present paper investigates the situation of the port of Marano Lagunare (Italy) by means of a bidimensional morphological-hydrodynamic and spectral coupled model. To reduce the sediment input into the port, the closure of a secondary port entrance is usually suggested. However, this work demonstrates that a complete dredging of the secondary port inlet allows for an increase in water circulation or efficiency renewal, which ensures a better oxygenation at the bottom of the canals.
\end{abstract}

Keywords: lagoon port; fine sediments; wave-current interaction; morphodynamic modelling

\section{Introduction}

Since ancient times, ports have served as a safe shelter for boats for all civilizations, to protect them from waves, storm surges or river currents depending on their specific location. For this reason, defense works are built to reduce the speed of the current and the wave motion inside the ports themselves as much as possible. This guarantees the safety of boats and crews, but also promotes the deposition of sediments which enter the port carried by the current, however small it is. Once deposited, the sediments are barely re-suspended in the water column, and therefore they usually remain trapped in the port, which gradually silts up, with consequent difficulties for navigation [1].

Conscious of this contradictory situation, engineers and scientists have always tried to solve or at least mitigate the problem [2]. The first step should be a thorough understanding of the local hydrodynamics responsible for the water exchange between the basin and the surrounding environment, and, as a consequence, for the entry of sediments into the harbor [3]. Local currents strongly depend on the nature and form of the port itself [4]. Ports located along the banks of a river usually suffer greatly from the effect of the river flow [5], which separates at the upstream edge of the port entrance, forming a turbulent mixing layer, and hence generating an exchange flow entering the port basin through a horizontal diffusive process $[1,3,6,7]$. If this is the main entry mechanism for sediments into fluvial ports far from the sea, when the distance from the river mouth is reduced other factors grow in importance, such as the advective processes of tidal filling and emptying [6]. Moreover, an active role can also be played by density currents, which can arise from gradients in water density due to the rise of the salt wedge or in water temperature due to the release of fresh or warm water in the port or even in suspended sediment concentrations $[6,8]$. These mechanisms often coexist and are superimposed on each other $[9,10]$. Extensive 
experimental and numerical studies have been conducted, mainly in relation to the ports of northern Europe (e.g., [10-13]).

Lagoons are semi-enclosed transitional environments which are naturally sheltered from storm surges due to their conformation, and therefore they often represent privileged positions for the construction of ports [14]. Their internal hydrodynamics is mainly due to the tides, which penetrate through the tidal inlets and spread through the channel network, which consists of a complex system of bifurcating channels with decreasing water velocities and canal sizes when moving away from the mouths, landwards.

It is generally recognized that coarse sediments deposit earlier, having a larger fall velocity [15]; this means that the tidal current entering the lagoon loses its intensity and is unable to transport the sandy sediments for a long time. In fact, these sediments generally settle within a short distance of the mouth [16]. Thus, inside lagoons, where current speed and water depth are relatively low, wind waves become crucial for sediment transport despite their relatively short period $[17,18]$. In fact, waves locally generated on the shallow tidal flats [19] interact with tidal currents, originating bottom shear stresses able to pick up even the finest sediments [20]; these are then conveyed along the canals, and therefore can penetrate the lagoon ports.

This causes behaviors in harbor siltation to be very different depending on the port location. For example, in most fluvial and sea ports sediments are mostly located near the entrance of the basin, where the coarsest sediment fraction deposits as soon as the current decreases, while usually only the finest sediments can reach the furthest part of the basin, resulting in a non-uniformly distributed sedimentation [7,21-23]. Conversely, when the sediments entering the port are only fine-grained, as occurs in semi-enclosed basins like lakes or coastal lagoons, they can remain in suspension for a longer period thanks to a much lighter fall velocity, and they spread all over the harbor before they deposit as the speed of the current decreases, for instance, during slack tides, resulting in a more uniform spatial distribution.

In both cases, once in the harbor, it is very difficult for the sediment to escape, and it settles on the bottom [1]. Considering this, the best way to reduce siltation should be the reduction of exchange water and hence of sediment input. Great strides have been made in the understanding of the expected behavior of hydro- and sediment dynamics which have made it possible to identify some measures capable of hindering the deposit in some cases [24]. A typical example of these technologies are current deflection walls, which gently move the flow away from the inlet, and thus reduce the intensity of the turbulent mixing layer and the consequent exchange flow entering the port [25]. Furthermore, non-structural actions can be undertaken, such as agitation dredging methods, which help limit the deposition by keeping the sediment in suspension and facilitating its exit from the basin through water jets or mechanical devices [24]. Other interventions are aimed at confining silting to well-defined areas, which simplifies the dredging operations; for instance, sediment traps are very common where the inflowing current is slowed down, inducing local sediment deposition [26]. Moreover, the question about the optimal number of entrances to the port is also still highly debated. In fact, if some authors suggest having more openings to ensure a minimum speed of the current inside the port [3], others recommend reducing the mouths of ports to limit the water exchange with the environment and hence the sediment input $[27,28]$.

Nonetheless, in the literature there is a general agreement that no engineering intervention can completely prevent periodical maintenance dredging in ports to guarantee a safe navigation; consequently, a project for dredging operations is always necessary and should also include a detailed study of the methods and location of the disposal of any excess sediments. In recent years, environmental legislation relating to the repositioning of the dredged sediments has gradually become stricter, restricting traditional practices. In lagoons, in particular, the disposal of dredged sediments along navigable channels is often no longer allowed. Common techniques to overcome this issue consist in disposing of dredging materials outside the lagoon system, either at sea or creating bordered islands, 
inducing the progressive deepening of the lagoon with an increase in the area of subtidal flats, a diminution in the area of the saltmarshes and a general simplification of the initial natural patterns $[29,30]$. The idea that is usually suggested to reverse this trend is to keep the dredged sediments within the lagoon itself, restoring the eroded salt marshes, for example [31,32]. However, in this case it is necessary to guarantee the sediment quality, which should respect the legal limits in terms of the chemical and ecotoxicological compatibility between the sediments to be relocated and the areas of their destination [33-36]. Lagoons, as semi-enclosed basins, are usually potentially polluted environments, and thus this is not an analysis with a foregone conclusion. When these requirements are not fulfilled, sediments must be treated, with a significant increase in operation costs: on-site actions can be undertaken to improve the quality of the sediments [37], otherwise the sediments should be disposed of in landfills. Moreover, lagoons often suffer from low oxygenation, that can be tackled through the maintenance of a minimum velocity of water inside the port.

Therefore, if, on the one hand, it is desirable to contain and reduce the volume of sediments that are deposited in the port, on the other hand it becomes increasingly important to try to preserve their quality, in order to facilitate the inevitable dredging and disposal operations. In light of this, one option might be to open up more entrances to the ports.

With this in mind, in the present work, a morphodynamic analysis has been conducted on the port of Marano Lagunare, a small town overlooking the Marano and Grado lagoon, which is situated at the northern end of the Adriatic Sea, Italy (Figure 1). The study was conducted by means of a bidimensional numerical model, considering tidal currents, wind waves and their mutual interaction, which regulates the complex hydrodynamic flow and contributes to the re-suspension and transportation of fine sediments inside the port. In particular, an attempt to intensify the circulation within the port is proposed, to improve oxygenation, without excessively increasing the deposit. Therefore, the idea is to make the port work like a channel network, to ensure a sufficient recirculation. To this aim, the closure of a secondary entrance, which is a typical solution for fluvial and maritime ports, has been considered and compared to the opposite solution, which is the complete opening of the secondary entrance. This highlights the different behavior of the lagoon port, which can be considered as a channel system. Moreover, an accurate wind analysis has been carried out to give a comparative evaluation of any drawbacks due to increased sediment deposition. Petti and co-workers $[19,38]$ showed that fetch loses importance in the generation process of wind waves within a lagoon context, where the shallow water depths considerably limit the wave growth, thus becoming essential for a correct wave description. In this sense, water depth and wind intensity play a major role. The usual approaches consist in using a constant wind speed, which can be considered significant from a morphological point of view [39,40], or simulating a particular event [41,42]. However, in order to describe the morphological evolution over an annual scale, in the present work the significant conditions for an average year have been considered, in terms of both frequency and event duration.

In Section 2 the study site is presented, and in Section 3 the bidimensional numerical model employed to analyze the hydro- and sediment dynamics is briefly described. The simulation setup is illustrated in Section 4, where the available data have been analyzed. An accurate preliminary analysis of environmental data that induce sediment transport and deposition is carried out, which is essential for a better understanding of the physical phenomena underlying the problem. Finally, in Section 5 the reference configuration and some engineering solutions are considered and carefully assessed. 


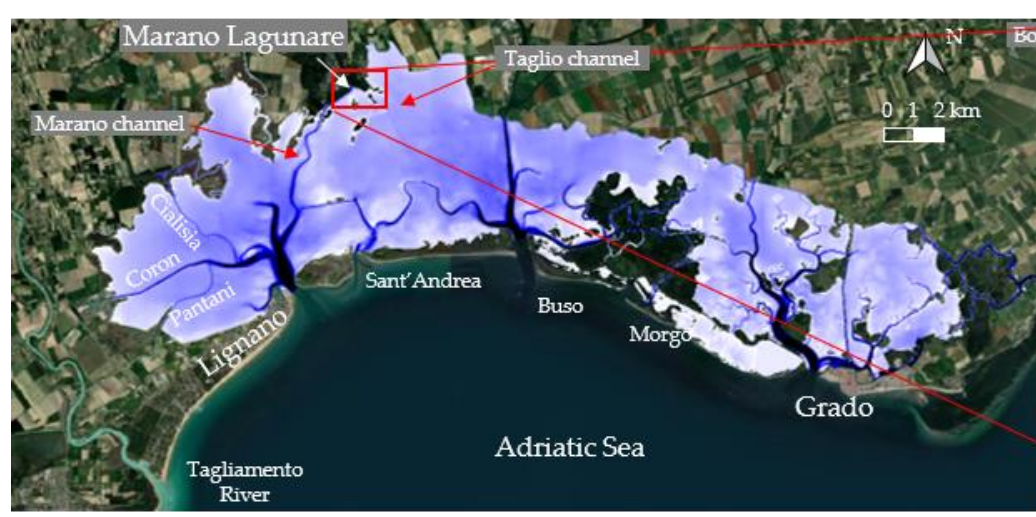

(a)

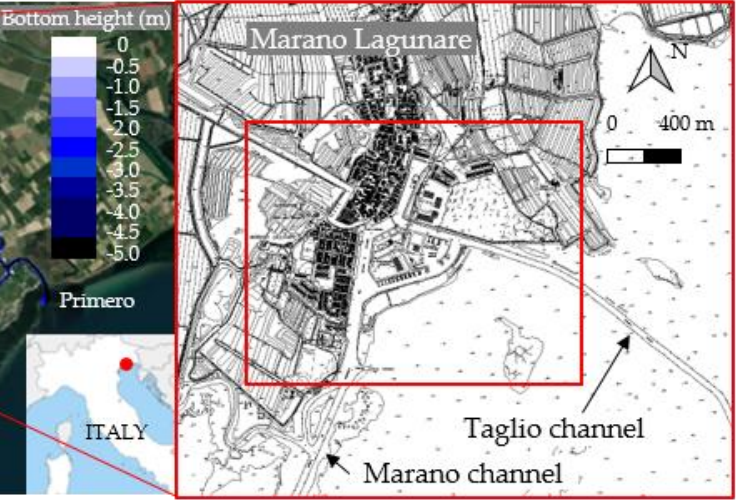

(b)

Figure 1. (a) The Marano and Grado lagoon in the northern Adriatic Sea, Italy: bathymetry data arising from the survey by Triches et al. [43] superimposed onto World Imagery satellite imagery (QGIS); (b) a detail of the regional cartography from 2003 of the Marano Lagunare area (http:/ / www.regione.fvg.it/rafvg/cms/RAFVG/ accessed on 1 September 2021); the red rectangle delimits the area depicted in Figure 2.
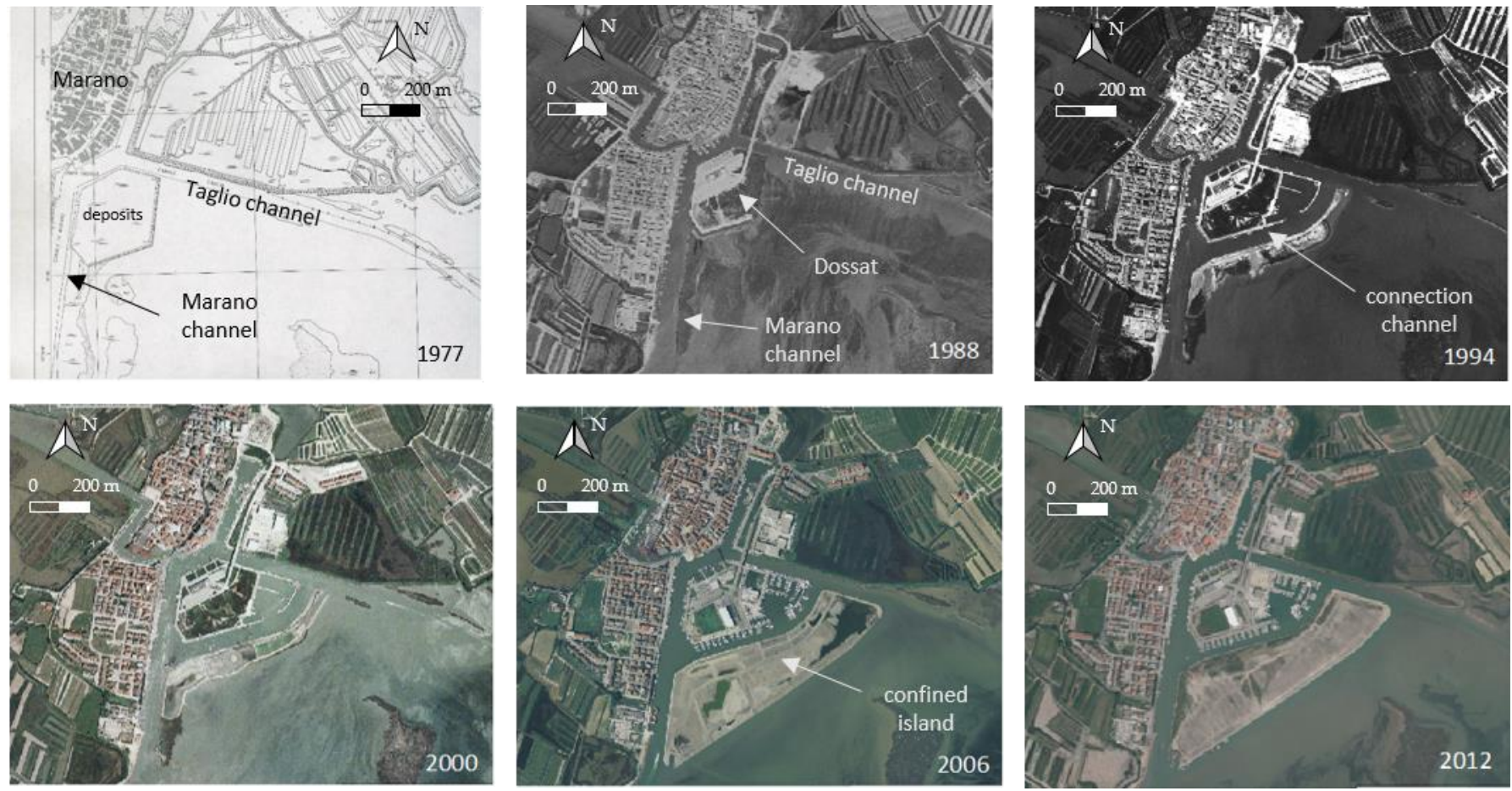

Figure 2. Historical evolution of the port of Marano Lagunare from 1977 to 2012 (red rectangle in Figure 1b). The 1977 image is the regional cartography from 1977 (http:/ / www.regione.fvg.it/rafvg/cms/RAFVG/ accessed on 1 September 2021); 1988-2012 images originate from the Italian National Geoportal of the Environment Ministry (http://www.pcn. minambiente.it/mattm/ accessed on 18 August 2021).

\section{Study Site}

The Marano and Grado Lagoon is located at the northern end of the Adriatic Sea, Italy, between the river mouths of the Tagliamento and Isonzo rivers, and it stretches for roughly $30 \mathrm{~km}$ East-West and $5 \mathrm{~km}$ in the North-South direction (Figure 1).

The lagoon is connected to the sea by six tidal inlets through which the tide enters the main channels and spreads all over the basin, guaranteeing the water exchange and determining the dominant currents. Maximum currents inside the lagoon are encountered at the tidal inlets, with maximum velocities ranging between 0.8 and $1.2 \mathrm{~m} / \mathrm{s}$ depending on the inlet, and mean velocities ranging between 0.5 and $0.7 \mathrm{~m} / \mathrm{s}$ [44]. Conversely, on 
the tidal flats, the flow velocity rarely exceeds $0.25 \mathrm{~m} / \mathrm{s}$ [20]. Marano Lagunare (usually simply referred to as Marano) is a small historical town, first built as a fishing community and already established during the ancient Roman period. It is located at the northernmost edge of the lagoon, far from the tidal inlets, and it probably evolved precisely because it represented a safe harbor and a shelter for navigation as well as a commercial site between the sea and the hinterland. Nowadays, the economy of Marano is still mainly based on fishing and tourism, both activities strictly related to navigation and to the presence in the town of both fishing and recreational ports.

From a historical point of view, the port system of Marano has undergone a profound transformation over the last 40 years, related to the permanent siltation process, which requires periodic maintenance works. As shown in Figure 2, in front of the village in 1977 there was only an accumulation of deposits, probably deriving from the traditional ancient dredging of the Marano and Taglio channels. In 1988 an accumulation of deposits became an urbanized area called Dossat island, and in 1994 it appears in its current outline, including the new recreational port. Moreover, a new deposit area is clearly recognizable in front of Dossat island, which includes the islands that mark the Marano channel. In this way, a new canal that connects the Marano canal to the Taglio canal was formed, which is usually referred to as the connection channel.

In 2000, this new deposit area was chosen as a confined island, where sediments deriving from dredging operations were disposed of, allowing for maintenance works inside the lagoon. Aerial pictures show how it has been filled over the years, with polluted sediments too, which were not allowed to be disposed of elsewhere, arising from lagoon channels. In 2012 the new artificial island reached its maximum retaining capacity, and in the following years it was covered by wild and uncultivated vegetation (Figure 2).

Recently, the silting of port canals has raised questions related to the chemical-physical and above all the ecotoxicological compatibility of the dredged matters with the new disposal areas. This issue was particularly evident during the maintenance works planned for 2019 [45-48].

In fact, the last complete dredging of the port system was carried out in 2015, reaching a minimum water depth of $2.5 \mathrm{~m}$ almost all over the port, as depicted in Figure 3a. In 2019, navigation safety required new dredging works, and hence a new survey was executed. This revealed a general increase in bottom height all over the basin (Figure 3b). The difference between these consecutive surveys gives a deposition over 4 years (Figure 4), which is about $48,850 \mathrm{~m}^{3}$ inside the black polygon of Figure 3a, indicating a mean siltation rate of about $9 \mathrm{~cm} /$ year. Even though the largest deposition of about $150 \mathrm{~cm}$ is located at the widening between Marano and the connection channels, significant deposits are also detected all over the port. This indicates that sediments are carried into the innermost part of the port, before they deposit, suggesting the presence of very fine sediments. This is consistent with the results of the granulometric analysis performed in 2019 over several points inside the port, both on the Marano canal and on the Taglio canal, which highlight a considerable uniformity of sediment size, with a substantial absence of sand $(0.26 \%)$, a clear preponderance of silts $(70.50 \%)$ and a consistent percentage of clay $(29.24 \%)$. The mean diameter can be evaluated as $18 \mu \mathrm{m}$.

However, at the same time, environmental analyses highlighted significant ecotoxicological problems spread across the entire port system, which prevented any operations to be carried out [45-48].

In order to improve the sediment management inside the harbor, an in-depth study of sediment dynamics has been conducted for a better understanding of the main physical processes behind it and to provide engineering solutions to mitigate the problems related to port silting. 


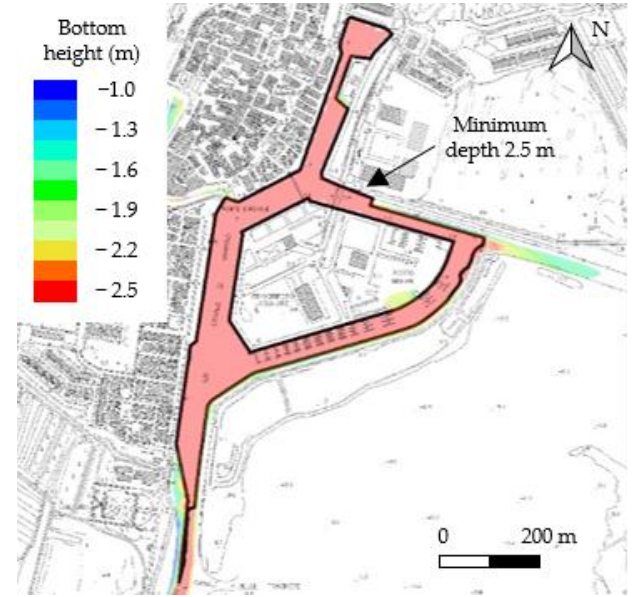

(a)

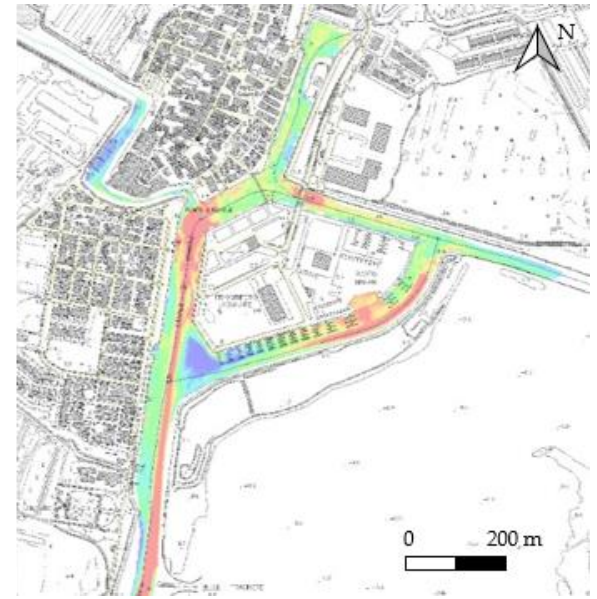

(b)

Figure 3. Consecutive surveys in the port: bottom height superimposed onto regional cartography from 2003. (a) Bottom height after the dredging works in 2015; the black line indicates the area where a minimum water depth of $2.5 \mathrm{~m}$ is guaranteed; (b) Bottom height in 2019.

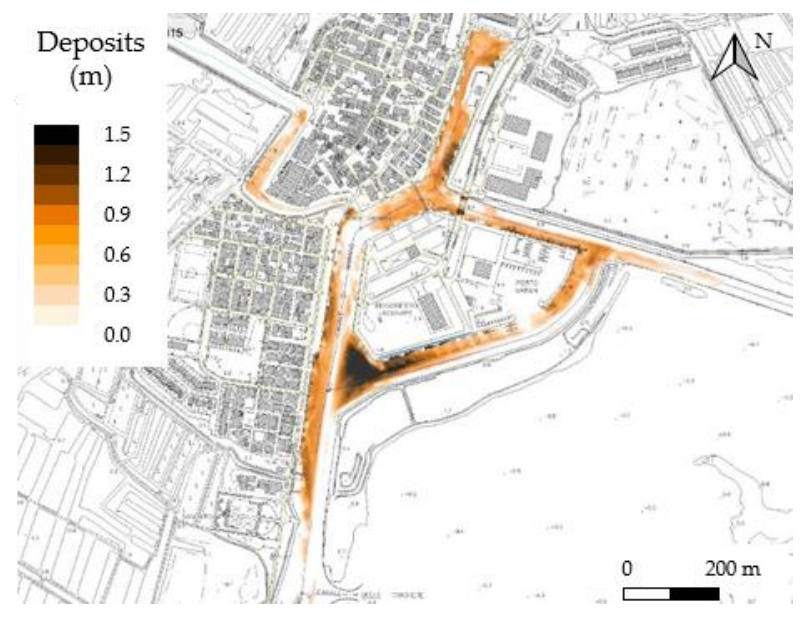

Figure 4. Sediment deposition occurring between 2015 and 2019 superimposed onto regional cartography from 2003.

\section{Numerical Model}

A true designation of sediment dynamics inside the harbor starts from a correct estimate of sediment input and hydrodynamic currents. For this reason, a wider domain than the port should be studied, with a numerical model able to properly describe the complex non-linear interaction between tidal currents and wind waves, and their effects on sediment transport. In the present work, this has been achieved by coupling a morphological-hydrodynamic model and a fully spectral wind-wave model.

The former is a bidimensional (2DH) finite volume shallow water in-house model, based on hydrodynamic equations, advection-diffusion equations of granular and cohesive suspended sediment concentration and a continuity equation of sediments at the bottom, as described in $[38,49]$. These equations allow the temporal bed evolution to be estimated by also taking into account the forcings due to the radiation stress tensor and the contribution of the wave motion to the bottom shear stresses $\tau_{b}$, which is evaluated according to Soulsby [50] as a nonlinear combination of the amount due to the current and the wave motion. Radiation stress terms and wave motion characteristics are calculated by SWAN [51] (https: / / swanmodel.sourceforge.io / accessed on 2 July 2020), an open-source third-generation model which integrates the wave action balance equation including all 
source terms, and hence also using the actual water level, currents and bottom height, as computed by the morphological-hydrodynamic model. The interaction between the two models is managed by a main program that runs them alternately until the simulation ends, exchanging input and output data on a common grid.

Unlike Petti et al. [38], granular sediments have been neglected in the present work, due to evidence that emerged from the surveys, thus allowing for a significant reduction in the complexity of the computational model.

The description of the sediment exchange processes between the water column and the bottom, which can be summarized through erosion and deposition, is recognized as one of the most challenging tasks in the study of fine sediment dynamics. In particular, most of the authors in the literature adopt the same structure of equations to evaluate the mass erosion $E_{M}$ and the deposition $D_{M}$ rates, i.e., Partheniades's [52] and Krone's [53] universally used erosion and deposition formula, respectively:

$$
E_{M}=\max \left(0, M_{P}\left(\frac{\tau_{b}-\tau_{e}}{\tau_{e}}\right)^{n_{P}}\right) ; D_{M}=\max \left(0, \rho_{s} w_{s}\left(1-\frac{\tau_{b}}{\tau_{d}}\right) c_{0}\right)
$$

with $M_{P}$ and $n_{P}$ being two coefficients, hereafter assumed as $0.001 \mathrm{~kg} /\left(\mathrm{m}^{2} \mathrm{~s}\right)$ and 1 , respectively [54]. $\rho_{s}$ is the grain density, $w_{s}$ the settling velocity here evaluated as in [54], and $c_{0}$ the near-bed concentration of suspended sediments, here set equal to the depth averaged sediment concentration, as a simple and often adopted choice [55].

$\tau_{e}$ and $\tau_{d}$ represent the critical bed shear stress for erosion and deposition, and there is still quite a heated debate on their evaluation. Even if a few formulas have been proposed to evaluate the critical bed shear stress for erosion (e.g., [56,57]) and deposition (e.g., [53,58]), most of the authors recognize that these parameters cannot be estimated a priori, because they are site-specific and can vary significantly between sites or even within the same reach. Therefore, there is still no reliable relationship based on sediment or environmental properties which can hold in general and for different situations. Thus, they must either be measured or calibrated (e.g., [59-63]).

Petti et al. [38] identified the critical bed shear stress for erosion, applying a morphological similarity with the critical values experimentally determined by Amos and co-workers within the Venice lagoon [64]. These values have been validated in [38] by means of the correspondence with the sediment deposition which occurs over an average year in a number of navigable channels. Since it is the same lagoon and it is subject to a similar annual analysis, the same values have also been adopted for the present simulation. In particular, $0.7 \mathrm{~Pa}$ has been adopted as the critical erosion threshold for navigable channels and permanently submerged mudflats, 1.3 Pa for intertidal flats occupied by seagrass, and 1.8 Pa for emerged sites or wet only by high tide. As regards the critical bed shear stress for deposition, an important line of research has been developed in the literature, which aims to experimentally deduce this value on the basis of laboratory analyses, often conducted on annular flumes (e.g., $[65,66])$. On the other hand, given the great variability in the results that can vary by even two orders of magnitude, and the difficulty in achieving field and laboratory measurements, $\tau_{d}$ often becomes a calibration parameter [67]. The value assumed in the present work is the result of a calibration process, where $\tau_{d}$ has been progressively adjusted to replicate the measured bed change between 2015 and 2019. The final selected value was $0.3 \mathrm{~Pa}$, which is consistent with laboratory data by Stone et al. [66] and with the rough estimate of about half the value of $\tau_{e}$ [54], which was set to $0.7 \mathrm{~Pa}$ in all navigable channels.

\section{Simulation Setup}

The choice of the computational domain is a key point in order to give a proper representation of the sediment input in the port. Even if the Marano harbor is relatively small, a larger area should be considered to give a consistent representation of the forcings that induce sediment movement. Petti et al. [38] showed that sediments in the lagoon are stirred up by the wave motion on the tidal flats and then driven by the tidal current along 
the channels. Moreover, preliminary studies showed that the water circulation inside the port is due to small differences in the water level and phase shifts at the entrances of the Marano and Taglio canals. Thus, the lagoon's hydrodynamics should be represented in the best possible way. Petti et al. [68] suggest imposing tidal oscillations on a sufficiently large domain directly into the Adriatic Sea, to appropriately describe the hydrodynamic evolution of the tides on the tidal inlets, and hence within the lagoon. Additionally, initial tests showed that the hydrodynamics of the western part of the lagoon, where Marano is located, is mainly influenced by the Lignano, Sant'Andrea and Porto Buso tidal inlets, allowing for the reduction of the computational domain and disregarding the eastern part of the lagoon, with the aim of limiting the computational effort. With this in mind, the study should include a large part of, but not the entire lagoon, the most influent tidal inlets and a portion of the Adriatic Sea, as shown in Figure 5. Sediments delivered by nearby rivers have been neglected, because most of them are resurgence waters, with very low sediment transport [38]. The resulting mesh consists of about 216,000 quadrangular elements, with a size length ranging between 0.8 and $550 \mathrm{~m}$. A detail of the port is depicted in Figure 5.

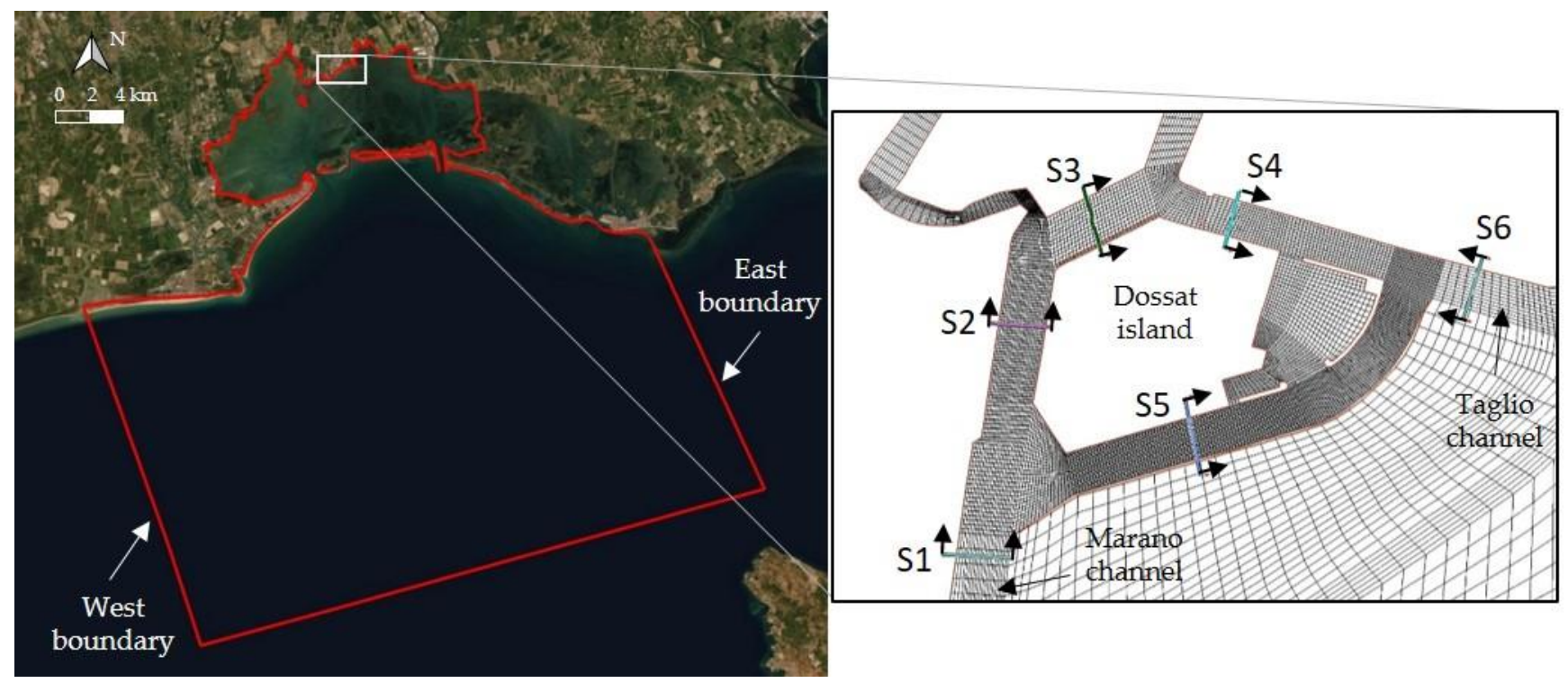

Figure 5. Morphodynamic computational mesh: mesh boundaries and a detail of the grid of the port of Marano, with the indication of the cross sections used in the following.

Manning roughness coefficients and the bottom height for the lagoon and the sea have been assigned as in Petti et al. [69], where the bottom height refers to the surveys conducted in 2009-2011 [43]. With reference to Manning roughness coefficients, the port channels were considered as lagoon channels, and the emerged artificial island in front of Marano was treated as dry land. The bottom height of the channels surrounding Marano was deduced from the post-dredging survey of 2015 (Figure 3a). The boundary conditions were assigned as in Petti et al. [68], imposing a tidal oscillation on the East and West sea boundaries and setting a reflective condition on all other boundaries. In this way, the influence of small rivers that flow into the lagoon was not taken into consideration, as they only influence the currents locally.

In addition to the validation process already conducted and presented in Petti et al. [38], the hydrodynamic model has been further verified by simulating a registered tidal oscillation and comparing the simulated and measured water surface levels at Marano's and Lignano's tidal gauges. The results are depicted in Figure 6, and they show a good agreement between numerical and observed data. 


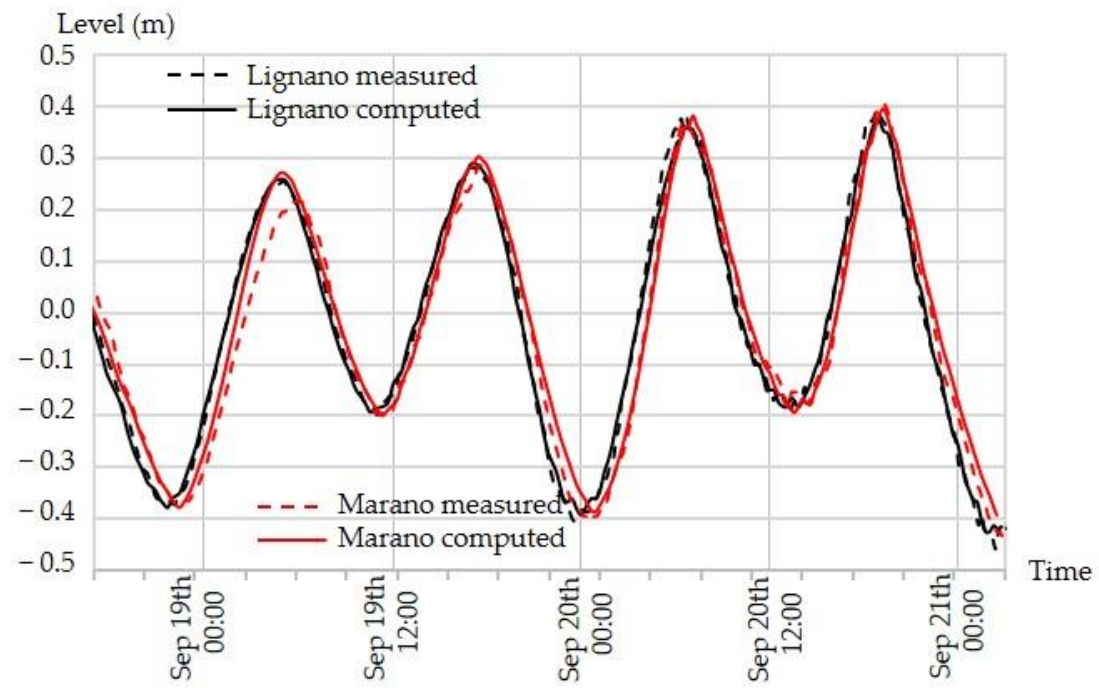

Figure 6. Comparison of measured (dashed lines) and computed (solid lines) water levels at the stations of Marano (red) and Lignano (black) in the period from 18 to 21 September 2014. Root-mean square errors over the entire simulation are evaluated as $0.018 \mathrm{~m}$ for Lignano data and $0.033 \mathrm{~m}$ for Marano data.

The hydrodynamics and sediment processes in the lagoon are induced by tidal currents and wind waves, which represent the main input of the numerical model. With this in mind, an accurate analysis of tides and winds was carried out, to identify the events responsible for port silting within an average year. In particular, the zero-crossing analysis conducted on the tidal oscillation recorded by the Grado tide gauge from 1991 to 2014 showed a mean amplitude of tidal wave height equal to $\pm 0.40 \mathrm{~m}$ [69]. For this reason, the tidal oscillation has been represented through a sine curve, having a period of $12 \mathrm{~h}$ and an amplitude equal to $\pm 0.40 \mathrm{~m}[69]$.

Petti et al. [38] have shown that the main morphodynamic changes within the lagoon are due to wind speeds exceeding $6 \mathrm{~m} / \mathrm{s}$ only. Thus, in the present work, wind events recorded between 1998 and 2004 at the Grado anemometer were identified as having an initial/final wind velocity of $2.5 \mathrm{~m} / \mathrm{s}$ and an average wind velocity over the entire duration higher than $6 \mathrm{~m} / \mathrm{s}$. These events have average directions belonging to the Bora and Sirocco sectors, identified in the following by the $75^{\circ} \mathrm{N}$ and $165^{\circ} \mathrm{N}$ directions, respectively. Generally speaking, Bora events appear as more regular and continuous, while Sirocco events seem to have a more variable direction, but only with slightly higher intensities. The selected events have been grouped according to their duration, as shown in Table 1, underlining the average number of events occurring every year, their mean duration and their average maximum and root-mean square velocities.

Table 1. Summary of selected events recorded at the Grado anemometer, grouped according to direction and event duration. For each class, the average annual number of events and their duration are specified, together with the average annual value of maximum and root-mean square (RMS) event velocities.

\begin{tabular}{cccccc}
\hline & $\begin{array}{c}\text { Duration } \\
\text { Classes }\end{array}$ & $\begin{array}{c}\text { Events } \\
\text { Number }\end{array}$ & $\begin{array}{c}\text { Duration } \\
(\mathbf{h})\end{array}$ & $\begin{array}{c}\text { Max Velocity } \\
(\mathbf{m} / \mathbf{s})\end{array}$ & $\begin{array}{c}\text { RMS Velocity } \\
(\mathbf{m} / \mathbf{s})\end{array}$ \\
\hline \multirow{3}{*}{ Bora } & $0-48 \mathrm{~h}$ & 5.9 & 26.2 & 11.2 & 6.9 \\
& $48-96 \mathrm{~h}$ & 2.9 & 64.7 & 11.0 & 6.7 \\
\multirow{2}{*}{ Sirocco } & $>96 \mathrm{~h}$ & 1.1 & 169.0 & 13.7 & 7.6 \\
\hline
\end{tabular}


As the wind forcing representative of an average year, a single event was chosen for each wind direction and class duration, which has an intensity equal to its root-mean square velocity and the cumulative duration of all the events in the class. Moreover, in the simulations, a morphological factor equal to 10 was used, which allows for changes in the bottom height to be amplified, in order to reduce computational times [70].

In order to gain a better understanding of the phenomena underlying the sediment dynamics in the port and assuming a principle of effect superimposition, it was decided to simulate the Bora and Sirocco events separately. Thus, Figure 7 summarizes the tidal oscillation and wind forcing which were adopted to simulate the morphodynamic effects of an average year, splitting the Bora and Sirocco simulations.

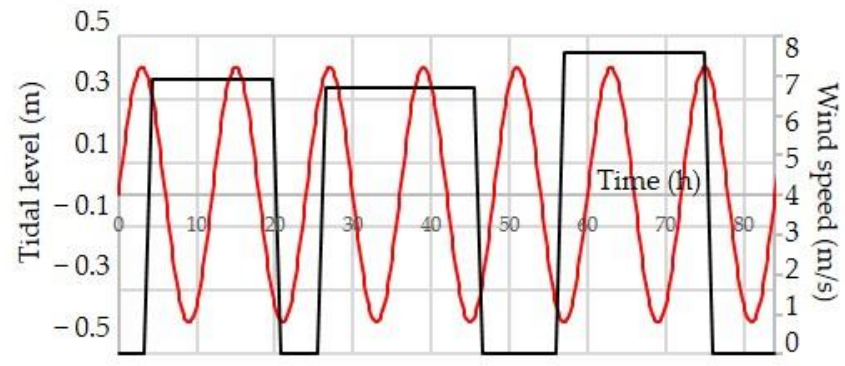

(a)

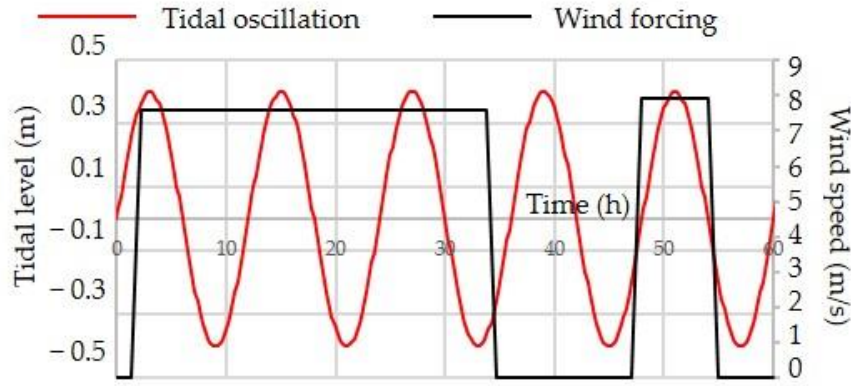

(b)

Figure 7. Wind and tidal forcings: (a) Bora events superimposed to tidal oscillations; (b) Sirocco events superimposed to tidal oscillations.

As the initial conditions, the current and water levels were assumed exactly as they resulted from a simulation of a few tidal oscillations with no wind forcings.

In order to verify the morphodynamic approach under the new tidal and wind forcings, the model has been further validated, following the same approach used by Petti et al. [38]. Thus, the sediment volumes which have been deposited in some navigable channels at the end of the simulated average year have been computed and compared with the mean annual volumes dredged by the Regional Authorities. The results are summarized in Table 2, where the comparison for the Marano, Cialisia, Coron and Pantani channels (see Figure 1) is shown. The correspondence between numerical values and dredged volumes is satisfactory, with a very small error, in particular, on the Marano channel, which is the most influent one for the purpose of the present study. This also corroborates the new approach used to describe the wind forcing, considering the duration of most intense events instead of their frequencies.

Table 2. Comparison of the simulated deposited volumes of sediments with the average annual dredged volumes.

\begin{tabular}{ccc}
\hline Channel & $\begin{array}{c}\text { Average Annual Dredged Volumes } \\
\left(\mathbf{m}^{\mathbf{3}} \mathbf{)}\right.\end{array}$ & $\begin{array}{c}\text { Simulated Deposited Volumes } \\
\left(\mathbf{m}^{\mathbf{3}} \mathbf{)}\right.\end{array}$ \\
\hline Marano & 11,050 & 10,920 \\
Cialisia & 8600 & 10,180 \\
Coron & 21,750 & 18,850 \\
Pantani & 9800 & 10,140 \\
\hline
\end{tabular}

\section{Results and Discussion}

\subsection{Reference Configuration}

For a thorough understanding of the sediments and hydrodynamics inside the harbor, the numerical model was first applied to the mesh with the same bottom height, as it was just after the dredging operations of 2015 (Figure 3a), and this has been considered hereafter as the reference configuration. In particular, three simulations have been conducted, the 
first being characterized by tide only, with no wind, the second by tide and Bora wind (Figure 7a) and the third by tide and Sirocco wind (Figure $7 \mathrm{~b}$ ).

The hydrodynamic behavior is similar in all three simulations, i.e., during the flood, the flow enters in through the Marano channel and exits through the Taglio channel, then vice versa in the ebb. The highest velocities are reached during the rising tidal phase, and precisely with the Bora wind (Figure 8).

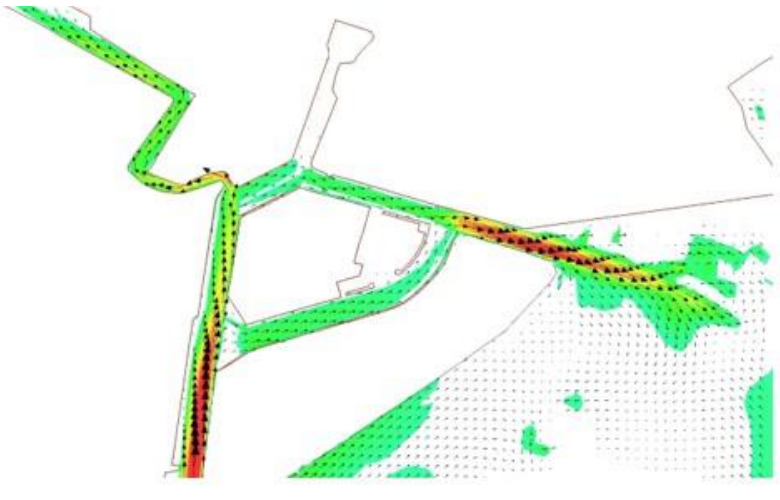

(a)

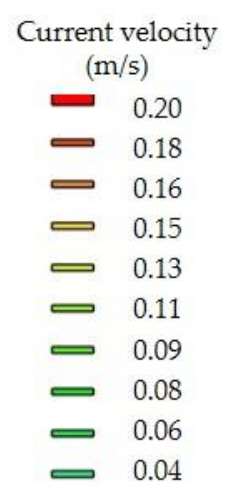

Figure 8. Simulation of Bora and tidal oscillations. Contour and vectors of the maximum current: (a) during flood tide; (b) during ebb tide.

In all cases, velocities are very low in the area where the Marano channel crosses the connection channel, especially along the quay, and this condition causes the silting of suspended matter entering the port. This is also confirmed by the surveys, which show the largest deposition exactly in this area (Figure 4). The general evolution of the flow in the port is summarized in the hydrographs of Figure 9, where it can be observed that the discharge through the Marano channel (Section S1) is the largest in all simulations, while the flow through the Taglio channel (Section S6) is smaller and in the opposite phase. Moreover, a comparison between the Bora and Sirocco simulations (Figure 9a,b) highlights the different behavior of the Marano and Taglio channels under different wind conditions. In fact, the flow entering the $\mathrm{S} 1$ section is larger during the Bora simulation than during the Sirocco simulation. On the contrary, the flow entering the $\mathrm{S} 6$ channel is slightly higher during the Sirocco event than during the Bora event.

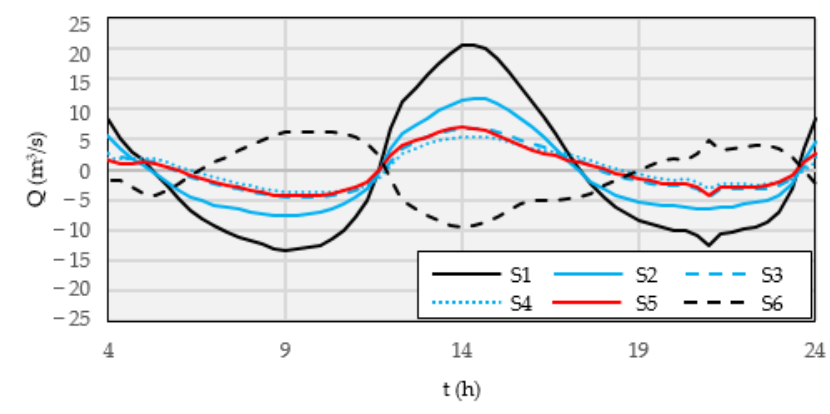

(a)

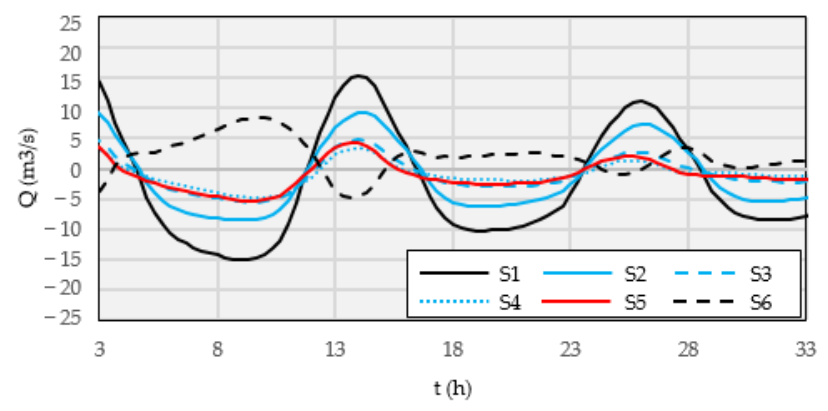

(b)

Figure 9. Water flow through selected cross sections indicated in Figure 5: (a) Hydrographs resulting from the Bora simulation; (b) Hydrographs resulting from the Sirocco simulation.

In terms of sediment transport, the simulation with only the tide does not make any contribution, further confirming the importance of wind-generated wave motion in the processes behind any sediment movement in a lagoon system. In both the Bora and Sirocco 
simulations, the maximum sediment concentrations enter the port through the Marano channel during the flood tide (Figure 10), and this is consistent with the fact that the maximum discharges are encountered here (Section S1 in Figure 9). However, lower but not insignificant sediment concentrations enter the port through the Taglio channel during the ebb tide, in particular for Sirocco events (Figure 11). The different penetration of the sediment concentration inside the port depending on the wind direction highlights the importance of the wind drag effect, which induces a setup in the lagoon that can strongly impact the current hydrodynamics. In this sense, the circulation system inside a lagoon port seems to be sensitive to both tides and winds. Thus, winds play a fundamental role not only in re-suspending sediments over tidal flats, and causing different suspended sediment concentrations at the Marano and Taglio port inlets, but also in influencing the currents in the port channels. This is an important feature that must be considered in order to study a lagoon port.

As a consequence, the average annual deposition in the port appears to be much more influenced by Bora events (Figure 12a), with a large silting of all channels, the only exception being the Taglio channel. On the other hand, Sirocco events are responsible for the siltation of the Taglio channel and make only a relatively small contribution to the sediment deposition in the Marano channel (Figure 12b). The sum of deposits of the Bora and Sirocco simulations gives only a distributed siltation inside the whole port as a result.

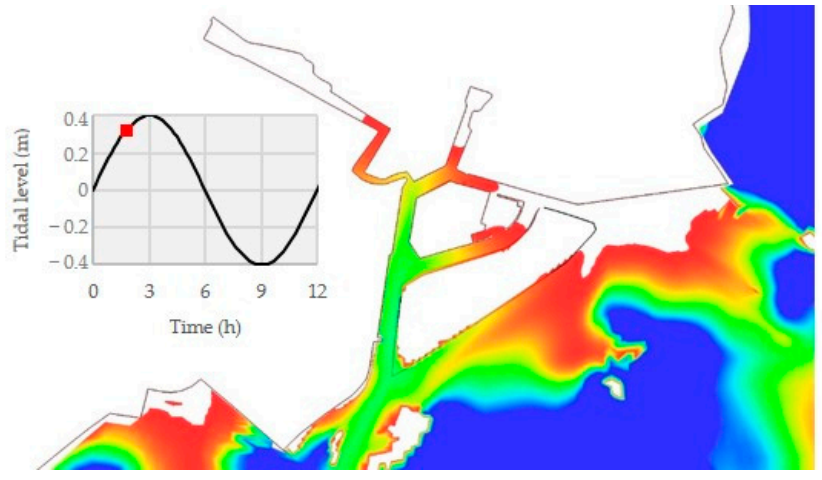

(a)

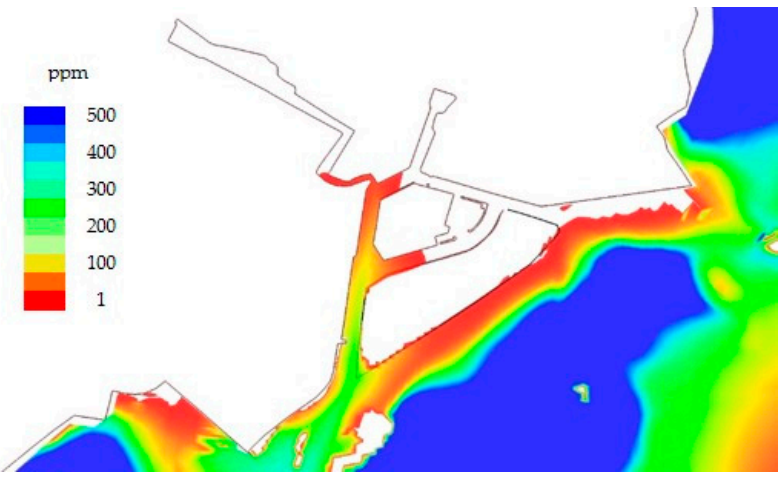

(b)

Figure 10. Contour of the maximum suspended sediment concentration during the flood tide: (a) Bora simulation; (b)'Sirocco simulation.

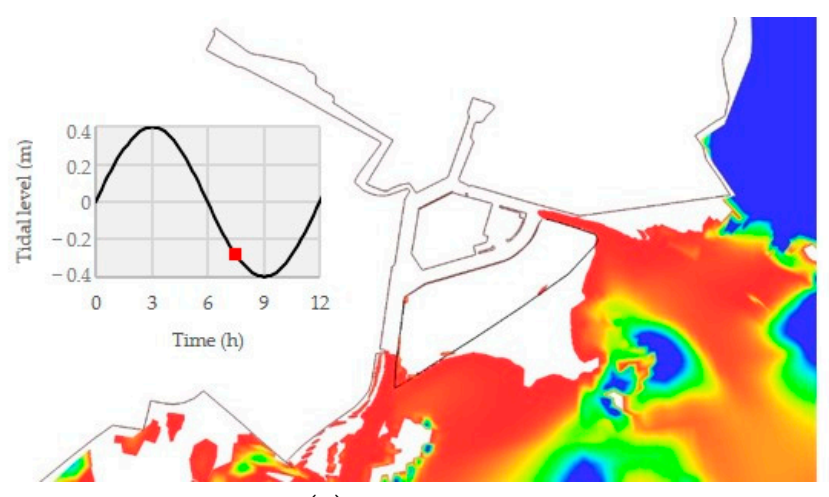

(a)

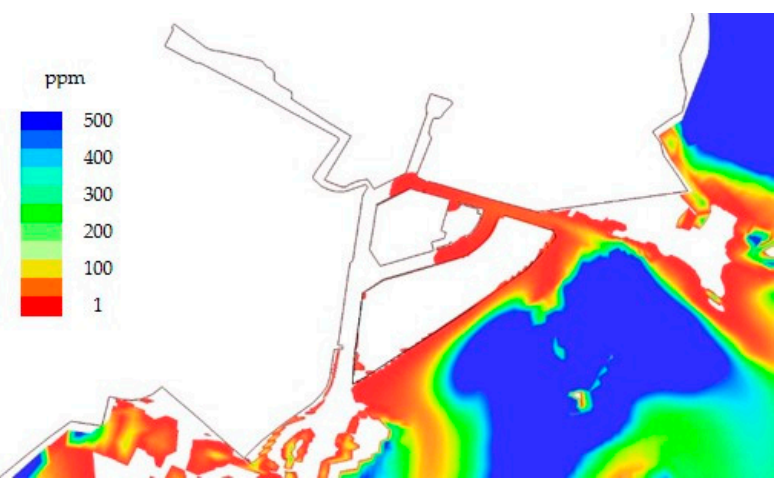

(b)

Figure 11. Contour of the maximum suspended sediment concentration during the ebb tide: (a) Bora simulation; (b) Sirocco simulation. 


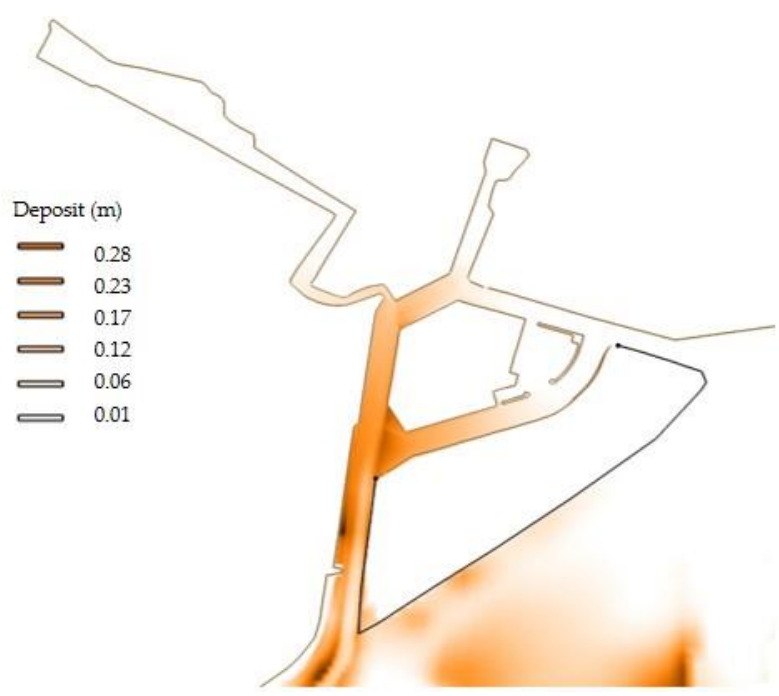

(a)

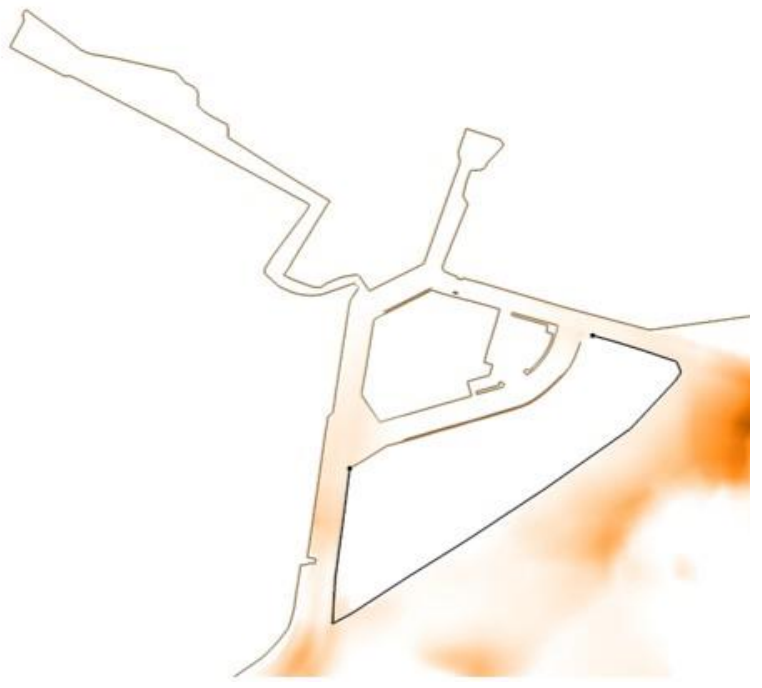

(b)

Figure 12. Sediment deposition at the end of the simulated average year: (a) Bora contribution; (b) Sirocco contribution.

\subsection{Closure of the Secondary Entrance}

Often, a larger sediment input inside the ports is observed where two entrances work at the same time, inducing a current between the two mouths which carries the suspended material up to areas which are also relatively distant from the inlets. This is typically the case of river ports [1], but similar situations can also be encountered in coastal areas [28]. In these cases, a possible solution is often the closure of one mouth, with a consequent decrease in sediments entering the port and a consequent limitation of dredging [27].

However, the incoming material is entrained in the water column by the action of wave motion on the tidal flats, and then it is dragged by the current into the port, regardless of the existence of the secondary inlet. Thus, the closure of one port inlet could result in only a small drop in dredging.

Moreover, the decrease of discharge due to the entrance closure would lead to a lower oxygenation of the sediments deposited on the bottom. In the case of fine sediments with a significant amount of organic matter, this could prove counterproductive, because it could cause a deterioration in sediment quality, making disposal difficult during unavoidable periodical dredging maintenance works.

With this in mind, an attempt was made to close the secondary entrance to the harbor, i.e., the Taglio channel, to better analyze the effects on port hydrodynamics. To this end, a dike was modeled in correspondence with Section S6 of Figure 5. A hydrodynamic simulation with tidal oscillation and no wind action was carried out, and a comparison with the reference configuration is shown in Figure 13 and Table 3 in terms of the discharge in the canals.

The results indicate that the flow would drastically decrease in all sections in the case of a complete closure of the Taglio channel, with a reduction ranging between $30 \%$ in Section S2 in the Marano channel and 80\% in Section S4 in the innermost part of the Taglio channel. If, on the one hand, it is true that the exchange water is reduced, on the other it is also true that it has not completely vanished, as in the Marano channel a significant discharge is still present, and therefore a sediment input will always exist. 


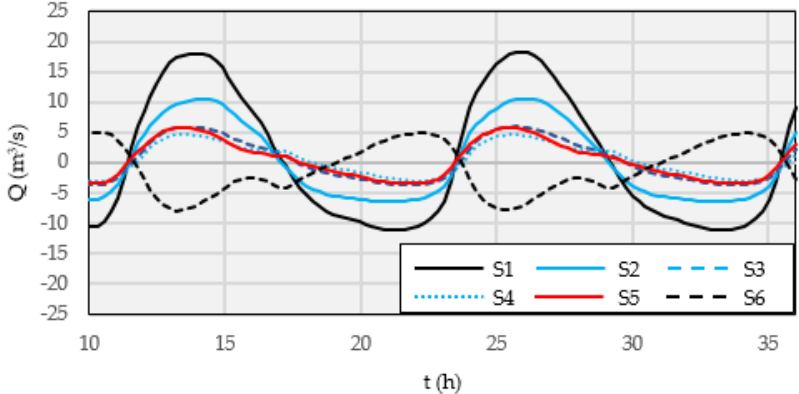

(a)

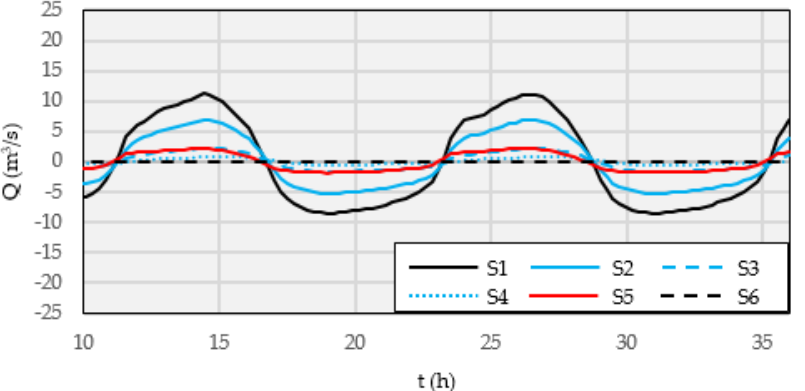

(b)

Figure 13. Water flow through selected cross sections resulting from tidal simulation with no wind forcings: (a) Reference configuration; (b) Closure of the Taglio channel.

Table 3. Maximum discharge $Q$ through selected cross sections resulting from the tidal simulation with no wind forcings, in the reference configuration and in the case of a complete closure of the Taglio channel.

\begin{tabular}{ccccccc}
\hline & \multicolumn{7}{c}{$Q\left(\mathrm{~m}^{3} / \mathbf{s}\right)$} \\
\cline { 2 - 7 } & $\mathbf{S 1}$ & $\mathbf{S 2}$ & $\mathbf{S 3}$ & $\mathbf{S 4}$ & S5 & S6 \\
\hline Reference configuration & 18.03 & 10.49 & 5.91 & 4.62 & 5.82 & 4.93 \\
Closure of Taglio channel & 11.27 & 7.01 & 2.22 & 0.78 & 2.29 & 0.00 \\
\hline
\end{tabular}

These results, together with the circulation pattern that emerged from the simulation on the reference configuration (Figure 8), suggest that the port can be considered as a hydraulic network, as schematized in Figure 14. The general circulation appears to be dominated by the water level and the current at the port entrances (Sections S1 and S6), which in turn are determined by the lagoon dynamics. The flow inside the port moves clockwise during the flood tide, when the flux entering the Lignano tidal inlet travels along the main lagoon channels, reaching Section S1 more quickly on the Marano channel, compared to Section S6 on the Taglio channel, which is quite distant from the deep channels. On the other hand, during the ebb tide, the flux finds a preferential way toward the sea in the Marano channel, determining a counterclockwise circulation inside the port.

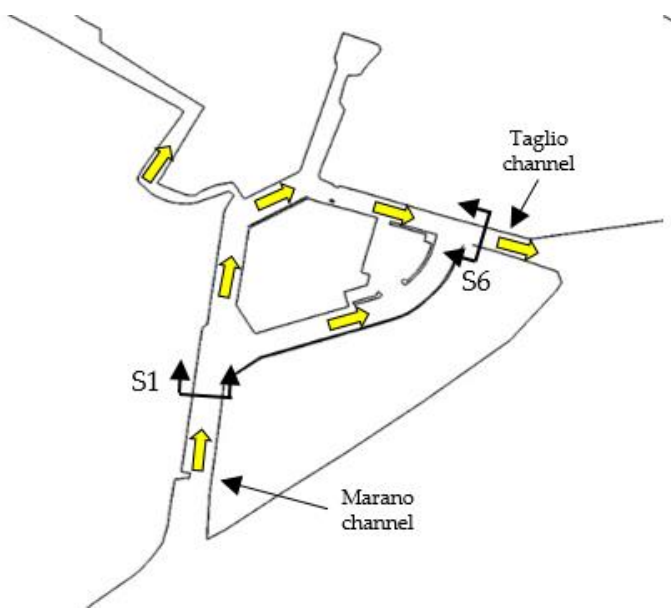

(a)

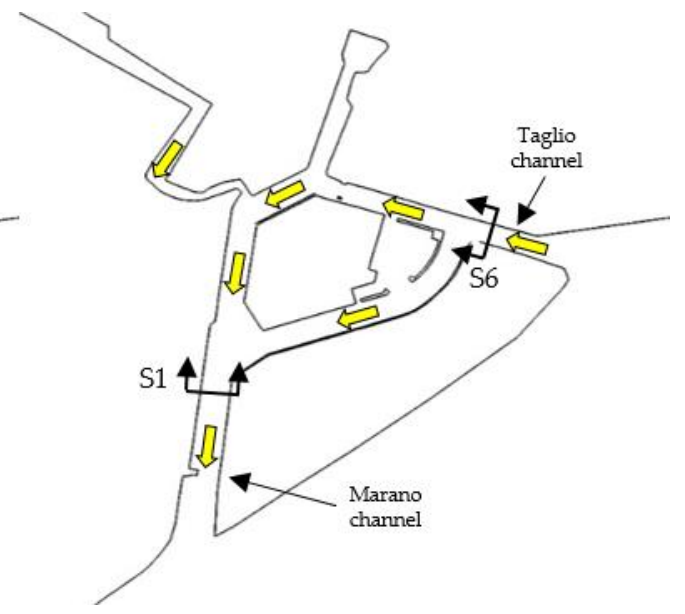

(b)

Figure 14. Sketch of the functioning of the Marano port as a hydraulic network during: (a) flood tide; (b) ebb tide. 
When this working principle is hindered, the water flow decreases, reaching the values shown in Table 3 in the extreme case of a complete closure of the Taglio channel. This underlines the key role of the second port entrance in this situation, and therefore it is very important to preserve and even improve its efficiency, not so much to avoid silting as to guarantee a better oxygenation of bed sediments and hence to facilitate decisional processes regarding the finding of a suitable disposal area.

\subsection{Dredging of the Taglio Channel}

In light of previous considerations, the computational mesh has been further modified, supposing a complete dredging of the Taglio channel, thus assigning to the Taglio channel the same bottom height of $-2.5 \mathrm{~m}$ of the dredged port, as depicted in Figure 15. On this configuration, three further simulations were conducted, the first being a simple tidal simulation and the other two a superimposition of the tide and the Bora and Sirocco winds respectively, as previously described. The results in terms of water discharge are illustrated in Figure 16, and in Table 4 the flow variations are calculated with regard to the corresponding simulation on the reference configuration.

The results indicate a general improvement in the hydrodynamic efficiency of the whole port network, with a flow intensification in all considered cross sections, and a mean increase of discharge in the innermost channel of 7.8\%, 10.4\% and 11\% (Sections S3, S4 and S5, respectively).

The rise in exchange water with the lagoon environment clearly implicates a higher sediment input in the port, with incremented siltation. This is confirmed by the volumes of deposition data displayed in Table 5, where the contribution of Bora and Sirocco events are simply added to give the total sediment amount. With regard to the reference configuration, the simulations with a dredged Taglio channel suggest a deposited sediment volume that is higher by $11.8 \%$. However, in the face of a relatively small increase in the volumes to be periodically dredged, the improvement in the sediment quality ensures much easier and cheaper dredging works.

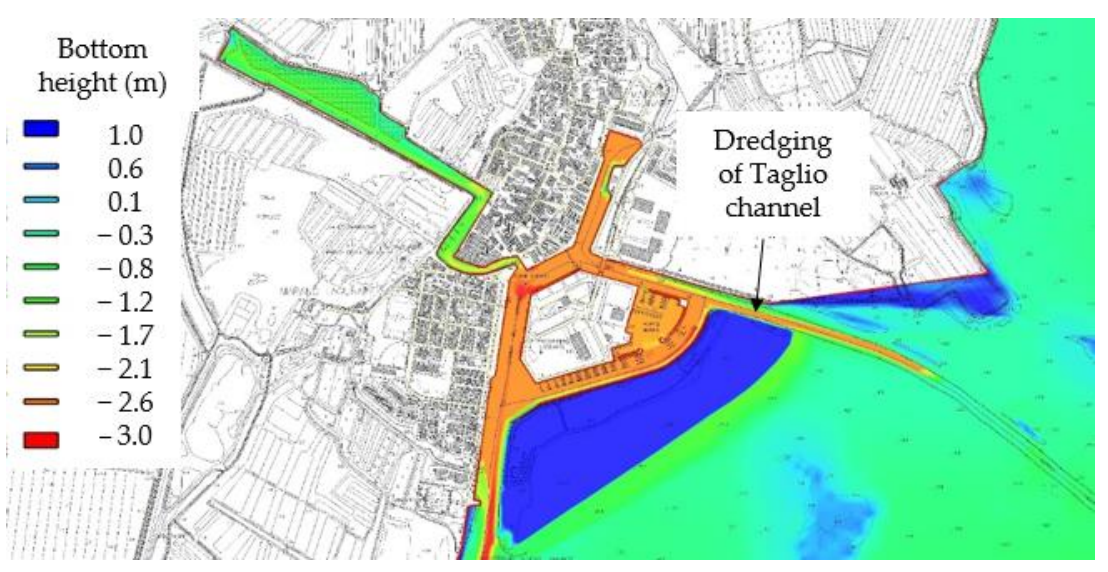

Figure 15. Bottom height of the new configuration, supposing a dredged Taglio channel. 


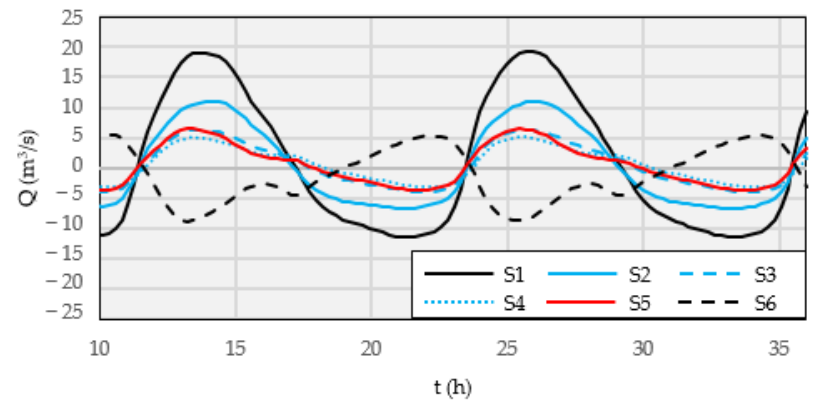

(a)

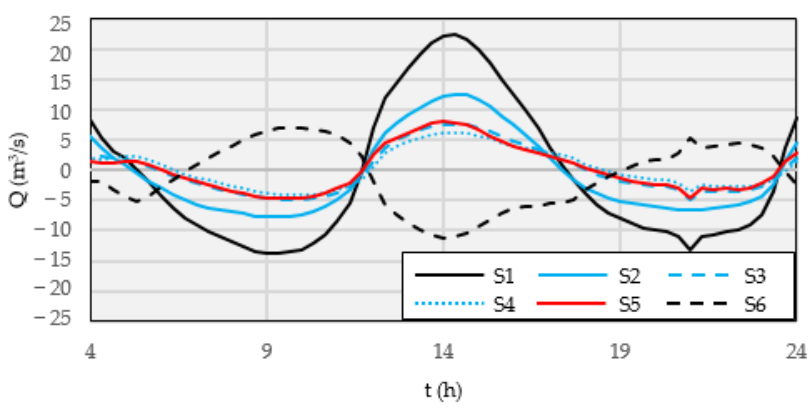

(b)

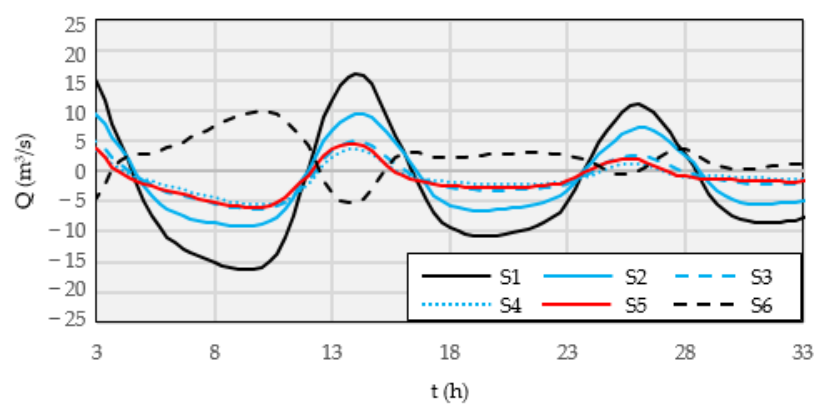

(c)

Figure 16. Simulations with a dredged Taglio channel. Water flow through selected cross sections: (a) Hydrographs resulting from the tidal simulation with no wind forcing; (b) Hydrographs resulting from the Bora simulation; (c) Hydrographs resulting from the Sirocco simulation.

Table 4. Simulations with a dredged Taglio channel. Flow variations with regard to the corresponding simulation on the reference configuration.

\begin{tabular}{ccccccc}
\hline & \multicolumn{7}{c}{$\Delta Q / Q \mathbf{~ ( \% )}$} \\
\cline { 2 - 7 } & S1 & S2 & S3 & S4 & S5 & S6 \\
\hline Tide only & +5.9 & +3.2 & +7.1 & +9.3 & +10.7 & +8.9 \\
Bora & +8.8 & +6.8 & +10.9 & +14.1 & +15.0 & +9.3 \\
Sirocco & +4.0 & +3.0 & +5.5 & +7.8 & +7.3 & +18.1 \\
\hline
\end{tabular}

Table 5. Volumes of sediment deposits in the Marano port at the end of the simulated average year.

\begin{tabular}{cccc}
\hline & \multicolumn{3}{c}{ Sediment Volume $\left.\mathbf{( m}^{\mathbf{3}}\right)$} \\
\cline { 2 - 4 } & Bora Simulation & Sirocco Simulation & Total Deposit \\
\hline Reference Configuration & 13,112 & 2769 & 15,881 \\
Dredged Taglio Channel Configuration & 14,676 & 3085 & 17,761 \\
\hline
\end{tabular}

\section{Conclusions}

The siltation problem of a lagoon port has been considered, starting from a historical reconstruction of the harbor development, which turned out to be closely related to the need for periodic dredging works. Nowadays, the port of Marano Lagunare is experiencing a generalized silting problem, which is worsened by pollution issues. In fact, as often happens in semi-enclosed environments like lagoons, the sediments inside the port are polluted and, in particular, they suffer from anoxia. This causes dredging works to be more complicated and expensive, because it becomes more difficult to find compatible disposal locations for the dredged sediments, according to environmental legislation. In 
the worst case, the sediments should be treated as polluted waste, with a strong increase in economic costs.

For a better understanding of the sediment dynamic inside the port, in the present work an attempt has been made to simulate the annual morphological changes that occur within the harbor, using a process-based hydrodynamic and morphological model. To this end, a numerical model, consisting in the coupling of a bidimensional morphologicalhydrodynamic model with a spectral model, was applied to a large part of the lagoon, focusing on the port. Moreover, an in-depth analysis of anemometric data was conducted to identify wind events, which can be considered as representative of an average year. All conducted simulations reveal very low discharges inside the port, for every wind condition. The resulting poor recirculation justifies the low oxygenation of the sediments, and hence their degradation.

Often, the reduction of the sediment input in the port is suggested as the best way to reduce port siltation, and this can be achieved by limiting the water exchange with the surrounding environment, for example by closing any secondary inlets. However, in the case of the port of Marano, simulations show that this would result in a drastic decrease in discharge values inside the port canals and, consequently, in a further worsening of the water and sediment quality. Thus, even if some advantages can be achieved with a certain decrease in the sediment volumes to be dredged, the sediment quality would deteriorate, making its disposal more complicated. In light of this and also given the relatively low silting rate of the port, the best choice appears to be an increase in the efficiency of the secondary entrance, and its maintenance as a dredged inlet, to ensure more easily manageable deposits. In fact, the numerical simulations of the average year indicate that an adequate water depth of the Taglio channel could considerably improve the water circulation everywhere within the port, with a relatively moderate increment in silted volumes.

This result suggests that in lagoon harbors, contrarily to what happens in fluvial or maritime ports, it is advantageous to avoid the closure of secondary entrances in order to maintain a sufficiently high flow velocity. This would not avoid port siltation, as sediments will inevitably deposit during slack tides, but it would contribute to maintaining a better water and sediment quality.

Moreover, the results clearly show that the tide does not bring any contribution to the sediment deposition inside the port in the absence of wind forcings. This fact enhances the importance of considering wind action when facing a silting problem in a lagoon port, wind generated wave motion being the main factor responsible for re-suspending sediments, which are then conveyed inside the port by the currents.

Furthermore, the analysis of the penetration of the sediment concentration inside the port during Bora and Sirocco events shows that wind direction can strongly influence the current circulation in the port channels, at the same instant in the tidal cycle. This is another point that makes lagoon ports different from fluvial or maritime ports, the circulation system being sensitive to both tides and wind, and this must be considered in order to give a proper interpretation of circulation systems.

Author Contributions: All the authors contributed equally to this work. All authors have read and agreed to the published version of the manuscript.

Funding: This research was co-funded by Regione Autonoma Friuli Venezia Giulia, Direzione centrale delle Infrastrutture e Territorio [CUP: D26D14000230002].

Institutional Review Board Statement: Not applicable.

Informed Consent Statement: Not applicable.

Data Availability Statement: The data presented in this study are available on request from the corresponding author. The data are not publicly available as they are internal reports of Regional Authority. Wind and tide measurements reported also by Petti et al. [38] are available at https: / / www.venezia.isprambiente.it/ (accessed on 15 July 2021). 
Conflicts of Interest: The authors declare no conflict of interest.

\section{References}

1. Van Rijn, L.C. Harbour Siltation and Control Measures. 2016. Available online: http:/ / www.leovanrijn-sediment.com (accessed on 15 July 2021).

2. Franco, L. Ancient Mediterranean harbours: A heritage to preserve. Ocean Coast. Manag. 1996, 30, 115-151. [CrossRef]

3. Winterwerp, J.C. Reducing Harbor Siltation. I: Methodology. J. Waterw. Port Coast. Ocean Eng. 2005, 131, 258-266. [CrossRef]

4. Langedoen, E.J.; Kranenburg, C.; Booij, R. Flow patterns and exchange of matter in tidal harbours. J. Hydraul. Res. 1994, 32, 259-270. [CrossRef]

5. Fernández, R.; Garcia, M.H.; Parker, G. Upper Mississippi River Flow and Sediment Characteristics and Their Effect on a Harbor Siltation Case. J. Hydraul. Eng. 2018, 144, 04018066. [CrossRef]

6. Langendoen, E.J. Flow Patterns and Transports of Dissolved Matter in Tidal Harbours. Ph.D. Thesis, Delft University of Technology, Delft, The Netherlands, 1992.

7. Lee, G.; Shin, H.J.; Kim, Y.T.; Dellapenna, T.M.; Kim, K.J.; Williams, J.; Kim, S.-Y.; Figueroa, S.M. Field investigation of siltation at a tidal harbor: North Port of Incheon, Korea. Ocean Dyn. 2019, 69, 1101-1120. [CrossRef]

8. de Nijs, M.A.J.; Winterwerp, J.C.; Pietrzak, J.D. On harbour siltation in the fresh-salt water mixing region. Cont. Shelf Res. 2009, 29, 175-193. [CrossRef]

9. Nasner, H. Siltation in tidal harbours, part I. Die Küste 1992, 127-170. (In German)

10. Vanlede, J.; Dujardin, A. A geometric method to study water and sediment exchange in tidal harbors. Ocean Dyn. 2014, 64, 1631-1641. [CrossRef]

11. Eysink, W.D. Impact of Sea-Level Rise on the Morphology of the Wadden Sea within the Scope of Its Ecological Function. Delft Hydraulics Internal Report. 1993. Available online: http:/ / resolver.tudelft.nl/uuid:ebccbef0-32fd-4f25-b1ad-2f0192f24996 (accessed on 28 July 2021).

12. Stoschek, O.; Zimmermann, C. Water Exchange and Sedimentation in an Estuarine Tidal Harbor Using Three-Dimensional Simulation. J. Waterw. Port Coast. Ocean Eng. 2006, 132, 410-414. [CrossRef]

13. Van Maren, D.S.; Winterwerp, J.C.; Sas, M.; Vanlede, J. The effect of dock length on harbour siltation. Cont. Shelf Res. 2009, 29, 1410-1425. [CrossRef]

14. Giaime, M.; Marriner, N.; Morhange, C. Evolution of ancient harbours in deltaic contexts: A geoarchaeological typology. Earth-Sci. Rev. 2019, 191, 141-167. [CrossRef]

15. Rouse, H. Engineering Hydraulics; John Wiley \& Sons: Hoboken, NJ, USA, 1950; ISBN 047174283X.

16. Carniello, L.; Defina, A.; D'Alpaos, L. Modeling sand-mud transport induced by tidal currents and wind waves in shallow microtidal basins: Application to the Venice Lagoon (Italy). Estuar. Coast. Shelf Sci. 2012, 102, 105-115. [CrossRef]

17. Cuadrado, D.G.; Gomez, E.A.; Pierini, J.O.; Federici, G.A. A Possible Solution to Rosales Harbour Excessive Siltation Rate (Bahìa Blanca Estuary, Argentina). J. Coast. Res. 2006, 1, 419-423.

18. Pascolo, S.; Petti, M.; Bosa, S. On the Wave Bottom Shear Stress in Shallow Depths: The Role of Wave Period and Bed Roughness. Water 2018, 10, 1348. [CrossRef]

19. Pascolo, S.; Petti, M.; Bosa, S. Wave Forecasting in Shallow Water: A New Set of Growth Curves Depending on Bed Roughness. Water 2019, 11, 2313. [CrossRef]

20. Petti, M.; Pascolo, S.; Bosa, S.; Bezzi, A.; Fontolan, G. Tidal Flats Morphodynamics: A new Conceptual Model to Predict Their Evolution over a Medium-Long Period. Water 2019, 11, 1176. [CrossRef]

21. Christiansen, T.; Wiberg, P.L.; Milligan, T.G. Flow and Sediment Transport on a Tidal Salt Marsh Surface. Estuar. Coast. Shelf Sci. 2000, 50, 315-331. [CrossRef]

22. Wallbrink, P.J.; Hancock, G.J.; Olley, J.M.; Hughes, A.; Prosser, I.P.; Hunt, D.; Rooney, G.; Coleman, R.; Stevenson, J. The Western Port Sediment Study; Consultancy Report; CSIRO Land and Water: Melbourne, Australia, 2003.

23. Shanehsazzadeh, A.; Ardalan, H. Regional-Scale Study on Sediment Processes of Khuran Strait at Persian Gulf with Implications for Engineering Design. China Ocean Eng. 2019, 33, 356-364. [CrossRef]

24. Kirby, R. Minimising harbour siltation-Findings of PIANC Working Group 43. Ocean Dyn. 2011, 61, 233-244. [CrossRef]

25. Purhoit, A.A.; Basu, A.; Chavan, K.A.; Kudale, M.D. Current Deflecting Wall: A Promising Structure for Minimising Siltation in Semi-Enclosed Docks. Int. J. Civ. Environ. Eng. 2017, 11, 121-129.

26. Theron, A.K.; Schoonees, J.S.; Claassens, H. Port of East London: Design and optimization of the sand traps. J. S. Afr. Inst. Civ. Eng. 2002, 44, 8-15.

27. Nasner, H. Siltation in tidal harbours, part II. Die Küste 1997, 63-114. (In German)

28. Huguet, J.R.; Brenon, I.; Coulombier, T.; Hamani, V. Dynamics and management of siltation in a macro-tidal marina: The case of La Rochelle marina, France. Ocean Coast. Manag. 2020, 198, 105371. [CrossRef]

29. Jeuken, M.C.J.L.; Wang, Z.B. Impact of dredging and dumping on the stability of ebb-flood channel systems. Coast. Eng. 2010, 57, 553-566. [CrossRef]

30. Sarretta, A.; Pillon, S.; Molinaroli, E.; Guerzoni, S.; Fontolan, G. Sediment budget in the Lagoon of Venice, Italy. Cont. Shelf Res. 2010, 30, 934-949. [CrossRef]

31. Stagg, C.L.; Mendelssohn, I.A. Restoring Ecological Function to a Submerged Salt Marsh. Restor. Ecol. 2010, 18, 10-17. [CrossRef] 
32. Guerra, R.; Pasteris, A.; Ponti, M. Impacts of maintenance channel dredging in a northern Adriatic coastal lagoon. I: Effects on sediment properties, contamination and toxicity. Estuar. Coast. Shelf Sci. 2009, 85, 134-142. [CrossRef]

33. Taupp, T.; Wetzel, M.A. Relocation of dredged material in estuaries under the aspect of the Water Framework Directive-A comparison of benthic quality indicators at dumping areas in the Elbe estuary. Ecol. Indic. 2013, 34, 323-331. [CrossRef]

34. Scheffler, A.; Roth, T.; Ahlf, W. Sustainable decision making under uncertainty: A case study in dredged material management. Environ. Sci. Eur. 2014, 26, 7. [CrossRef]

35. Toumazis, A.D. Environmental impact associated with the dumping of dredged material at sea. A study for the Limassol port extension works. Water Sci. Technol. 1995, 32, 151-158. [CrossRef]

36. Somerfield, P.; Atkins, M.; Bolam, S.; Clarke, K.R.; Garnacho, E.; Rees, H.L.; Smith, R.; Warwick, R.M. Relative impacts at sites of dredged-material relocation in the coastal environment: A phylum-level meta-analysis approach. Mar. Biol. 2006, 148, 1231-1240. [CrossRef]

37. Cecchi, G.; Vagge, G.; Cutroneo, L.; Greco, G.; Di Piazza, S.; Faga, M.; Zotti, M.; Capello, M. Fungi as potential tool for polluted port sediment remediation. Environ. Sci. Pollut. Res. 2019, 26, 35602-35609. [CrossRef]

38. Petti, M.; Bosa, S.; Pascolo, S. Lagoon Sediment Dynamics: A Coupled Model to Study a Medium-Term Silting of Tidal Channels. Water 2018, 10, 569. [CrossRef]

39. Umgiesser, G.; Sclavo, M.; Carniel, S.; Bergamasco, A. Exploring the bottom stress variability in the Venice Lagoon. J. Mar. Syst. 2004, 51, 161-178. [CrossRef]

40. Fagherazzi, S.; Carniello, L.; D'Alpaos, L.; Defina, A. Critical bifurcation of shallow microtidal landforms in tidal flats and salt marshes. Proc. Natl. Acad. Sci. USA 2006, 103, 8337-8341. [CrossRef]

41. Mariotti, G.; Fagherazzi, S. Wind waves on a mudflat: The influence of fetch and depth on bed shear stresses. Cont. Shelf Res. 2013, 60, S99-S110. [CrossRef]

42. Shi, B.; Cooper, J.R.; Pratolongo, P.D.; Gao, S.; Bouma, T.J.; Li, G.; Li, C.; Yang, S.L.; Wang, Y.P. Erosion and Accretion on a Mudflat: The Importance of Very Shallow-Water Effects. J. Geophys. Res. Oceans 2017, 122, 9476-9499. [CrossRef]

43. Triches, A.; Pillon, S.; Bezzi, A.; Lipizer, M.; Gordini, E.; Villalta, R.; Fontolan, G.; Menchini, G. Carta Batimetrica Della Laguna di Marano e Grado; Arti Grafiche Friulane, Imoco spa: Udine, Italy, 2011; 39p, 5 Maps; ISBN 978-88-95980-02-7. (In Italian)

44. Dorigo, L. La Laguna di Grado e le sue Foci. Ricerche e Rilievi Idrografici; Magistrato alle Acque, Ufficio Idrografico: Venice, Italy, 1965. (In Italian)

45. D.Lgs.152/2006. Decreto legislativo, 03/04/2006 n 152, G.U. 14 April 2006. Available online: https:/ /www.camera.it (accessed on 1 October 2021). (In Italian)

46. D.M.173/2016. Decreto ministeriale, 15/07/2016 n 173, G.U. 6 September 2016. Available online: https:/ / www.gazzettaufficiale. it (accessed on 1 October 2021). (In Italian)

47. OGS. Campionamento e caratterizzazione dei sedimenti del Porto di Marano Lagunare finalizzato ai lavori di ricalibratura del fondale dei canali prospicenti l'abitato di Marano Lagunare. Internal Report. 2019. (In Italian)

48. ARPA-FVG. Laguna di Marano-Grado. Ricalibratura del fondale dei canali prospicienti l'abitato di Marano. Prot.0016630/P/GEN/PRA. 20 May 2019; PRA-AUT. Internal Report. 2019. (In Italian)

49. Bosa, S.; Petti, M.; Lubrano, F.; Pascolo, S. Morphodynamic Model Suitable for River Flow and Wave-Current Interaction. IOP Conf. Ser. Mater. Sci. Eng. 2017, 245, 062005. [CrossRef]

50. Soulsby, R.L. Dynamics of Marine Sands: A Manual for Practical Applications; Thomas Telford Publications: London, UK, 1997; 249p, ISBN 978-0-7277-2584-X.

51. Booij, N.; Ris, R.C.; Holthuijsen, L.H. A third-generation wave model for coastal regions, Part I, Model description and validation. J. Geophys. Res. 1999, 104, 7649-7666. [CrossRef]

52. Partheniades, E. Erosion and Deposition of Cohesive Soils. J. Hydraul. Div. 1965, 91, 105-139. [CrossRef]

53. Krone, R.B. Flume Studies of the Transport of Sediment in Estuarial Shoaling Processes, Final Report; Hydraulic Engineering and Sanitary Engineering Research Laboratory, University of California: Berkeley, CA, USA, 1962.

54. Whitehouse, R.J.S.; Soulsby, R.L.; Roberts, W.; Mitchener, H.J. Dynamics of Estuarine Muds; Thomas Telford: London, UK, 2000; ISBN 0727728644.

55. Winterwerp, J.C.; van Kesteren, W.G.M. Introduction to the Physics of Cohesive Sediment Dynamics in the Marine Environment; Elsevier: Oxford, UK, 2004; Volume 56, ISBN 0-444-51553-4.

56. Thorn, M.F.C.; Parson, J.C. Erosion of cohesive sediments in estuaries: An engineering guide. In Proceedings of the 3rd International Symposium on Dredging Technology, Bordeaux, France, 5-7 March 1980; BHRA: Cranfield, UK; pp. 349-358.

57. Mitchener, H.J.; Whitehouse, R.J.S.; Soulsby, R.L.; Lawford, V.A. Estuarine Morphodynamics. Development of SedErode-Instrument for In-Situ Mud Erosion Measurements; HR Wallingford Report TR 17; HR wallingford Ltd.: Wallingford, UK, 1996.

58. Kranenburg, C. Effects of floc strength on viscosity and deposition of cohesive sediment suspensions. Cont. Shelf Res. 1999, 19, 1665-1680. [CrossRef]

59. Briaud, J.L.; Ting, F.C.K.; Chen, H.C.; Cao, Y.; Han, S.W.; Kwak, K.W. Erosion Function Apparatus for Scour Rate Predictions. J. Geotech. Geoenviron. Eng. 2001, 127, 105-113. [CrossRef]

60. Huang, J.; Hilldale, R.C.; Greimann, B.P. Cohesive Sediment Transport. In Erosion and Sedimentation Manual; U.S. Department of the Interior Bureau of Reclamation: Washington, DC, USA, 2006; pp. 4-1-4-54.

61. Julian, J.P.; Torres, R. Hydraulic erosion of cohesive riverbanks. Geomorphology 2006, 76, 193-206. [CrossRef] 
62. Sanford, L.P.; Maa, J.P.-Y. A unified erosion formulation for fine sediments. Mar. Geol. 2001, 179, 9-23. [CrossRef]

63. Kombiadou, K.; Krestenitis, Y.N. Modelling Cohesive Sediment Dynamics in the Marine Environment. In Sediment Transport Processes and Their Modelling Applications; Manning, A.J., Ed.; IntechOpen: London, UK, 2013; Available online: https://www. intechopen.com/chapters/38257 (accessed on 1 October 2021). [CrossRef]

64. Amos, C.L.; Bergamasco, A.; Umgiesser, G.; Cappucci, S.; Cloutier, D.; DeNat, L.; Flindt, M.; Bonardi, M.; Cristante, S. The stability of tidal flats in Venice Lagoon-The results of in-situ measurements using two benthic, annular flumes. J. Mar. Syst. 2004, 51, 211-241. [CrossRef]

65. Maa, J.P.-Y.; Kwon, J.-I.; Hwang, K.-N.; Ha, H.-K. Critical Bed-Shear Stress for Cohesive Sediment Deposition under Steady Flows. J. Hydraul. Eng. 2008, 134, 1767-1771. [CrossRef]

66. Stone, M.; Krishnappan, B.G.; Granger, S.; Upadhayay, H.R.; Zhang, Y.; Chivers, C.A.; Decent, Q.; Collins, A.L. Deposition and erosion behaviour of cohesive sediments in the upper River Taw observatory, southwest UK: Implications for management and modelling. J. Hydrol. 2021, 598, 126-145. [CrossRef]

67. Lumborg, U.; Pejrup, M. Modelling of cohesive sediment transport in a tidal lagoon-An annual budget. Mar. Geol. 2005, 218, 1-16. [CrossRef]

68. Petti, M.; Bosa, S.; Pascolo, S.; Uliana, E. Marano and Grado Lagoon: Narrowing of the Lignano Inlet. IOP Conf. Ser. Mater. Sci. Eng. 2019, 603, 032066. [CrossRef]

69. Petti, M.; Bosa, S.; Pascolo, S.; Uliana, E. An Integrated Approach to Study the Morphodynamics of the Lignano Tidal Inlet. J. Mar. Sci. Eng. 2020, 8, 77. [CrossRef]

70. Roelvink, J.A. Coastal morphodynamic evolution techniques. Coast. Eng. 2006, 53, 277-287. [CrossRef] 